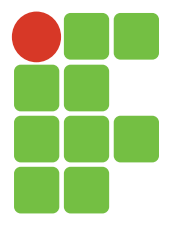

\title{
Dinâmica populacional de plantas daninhas em cultivares de alface produzidas no verão em Seropédica - RJ
}

Antônio de Amorim Brandão ${ }^{1}$

Eduardo Castro Ribeiro ${ }^{2}$

Cibelle Vilela Andrade Fiorini ${ }^{3}$

Aroldo Ferreira Lopes Machado 4

Higino Marcos Lopes ${ }^{5}$

\section{Resumo}

Diferenças na arquitetura em espécies de alface cultivadas podem levar a alterações nas populações de plantas daninhas no período de cultivo. Dessa forma, objetivou-se neste trabalho avaliar efeitos de cultivares de alface na supressão de plantas daninhas. Foram avaliadas 12 cultivares de alface dispostas no delineamento em blocos ao acaso, com três repetições. As parcelas constituíram-se de 12 plantas distribuídas em quatro linhas espaçadas em 0,30 m. As cultivares avaliadas foram do grupo lisa (Regina 2.000, Regina 500, Regina 3.500, Maravilha de Inverno, Boston Branca, Rainha de Maio); do grupo crespa (Grand Rapids, Hanson, Camila, Banchu Red Fire) e do grupo americana (Grandes Lagos, Delícia). A população de plantas daninhas foi avaliada aos 15 e 29 dias após o transplantio das cultivares. As plantas daninhas foram coletadas em um quadrado de 0,25 m de lado, lançadas ao acaso nas parcelas. Todas as plantas do interior do quadrado foram coletadas e identificadas, e o número de espécies e de indivíduos por espécie foi quantificado. Em seguida, esse material foi seco em estufa de circulação forçada a $65^{\circ} \mathrm{C}$ por 72 horas, até atingir massa constante. Determinou-se a frequência (F); densidade (D); dominância (DO); frequência relativa (FR); densidade relativa (DR); dominância relativa (DOR) e índice de valor de importância (IVI). As três principais plantas daninhas, com relação ao (IVI), identificadas nas duas coletas, foram a Cyperus esculentus L., Commelina benghalensis L. e Panicum maximum Jacq. As cultivares do grupo lisa Regina 500, Regina 2.000, Regina 3.500 e Rainha de Maio provocaram maior supressão de todas as espécies de plantas daninhas na segunda avaliação.

Palavras-chave: Lactuca sativa L. Hortaliças. Mato competição.

\footnotetext{
$1 \quad$ Universidade Federal Rural do Rio de Janeiro, aluno de doutorado (pós-graduação em fitotecnia). Seropédica, RJ, Brasil. toniagrick@hotmail.com. Rodovia BR 465 - Km 7, Campus Universitário, Seropédica, Rio de Janeiro, RJ. 23851-970.

2 Universidade Federal Rural do Rio de Janeiro. Seropédica, RJ, Brasil. eduardo_castro17@hotmail.com. Departamento de Fitotecnia, Rodovia BR 465 - Km 7, Campus Universitário, Seropédica, Rio de Janeiro, RJ. 23851-970.

3 Universidade Federal Rural do Rio de Janeiro, professor pesquisador. Seropédica, RJ, Brasil. cibellefiorini@yahoo.com.br. Departamento de Fitotecnia, Rodovia BR 465 - Km 7, Campus Universitário, Seropédica, Rio de Janeiro, RJ. 23851-970.

4 Universidade Federal Rural do Rio de Janeiro, professor pesquisador. Seropédica, RJ, Brasil. amachado@ufrrj.br. Departamento de Fitotecnia, Rodovia BR 465 - Km 7, Campus Universitário, Seropédica, Rio de Janeiro, RJ. 23851-970.

5 Universidade Federal Rural do Rio de Janeiro, professor pesquisador. Seropédica, RJ, Brasil. higinomlopes@gmail.com. Departamento de Fitotecnia, Rodovia BR 465 - Km 7, Campus Universitário, Seropédica, Rio de Janeiro, RJ. 23851-970.
} 


\section{Introdução}

Entre as hortaliças folhosas, a alface (Lactuca sativa L.) é a mais produzida. Possui grande importância, tanto para o sistema convencional quanto para o sistema orgânico de produção. A escolha da cultivar é decisiva para o sucesso do sistema de cultivo adotado (ECHER et al., 2001). Com os avanços do melhoramento genético da alface no Brasil, novas cultivares foram colocadas à disposição dos produtores. Conhecer o comportamento no ambiente de cultivo é importante, inclusive no que diz respeito ao manejo de plantas daninhas. Nesse sentido, cultivares que apresentem maior e mais rápida capacidade de cobertura do solo tendem a ter maior poder competitivo em relação às plantas daninhas.

As áreas de cultivo de olerícolas, principalmente de alface, caracterizam-se pelo uso intensivo do solo, com vários ciclos culturais em sequência durante o ano. Em geral, os solos são férteis, com elevado aporte de fertilizantes e baixa restrição hídrica; por consequência, nesses ambientes, predominam espécies ruderais, que exibem altas taxas de crescimento e formação de estruturas reprodutivas (FONTANÉTTI et al., 2004).

As plantas daninhas competem com a cultura de interesse pelos recursos do meio, principalmente água, luz e nutrientes, liberando substâncias alelopáticas, atuando como hospedeiras de pragas e doenças e interferindo nas práticas de colheita (ZANATTA et al., 2006). A presença de plantas daninhas, aliada ao mau manejo e ao uso de variedades olerícolas mais sensíveis à competição, influencia negativamente o processo produtivo por essa competição pelos recursos do meio. A interferência pode promover redução de 30 a 45\% na produtividade, quando ocorre nos primeiros estádios de desenvolvimento da cultura da alface; além disso, afeta a firmeza de suas folhas e, também, o conteúdo de nitrato e caroteno (GIANNOPOLITIS et al., 1989). Em culturas folhosas, as plantas daninhas ainda favorecem a umidade nas folhas, aumentando, assim, a incidência de doenças e diminuindo a qualidade do produto e o seu valor comercial (LORENZI, 2006).

De acordo com Pitelli (1985), o grau de interferência das plantas daninhas em relação às culturas depende de fatores ligados às espécies cultivadas (cultivar e espaçamento), às plantas daninhas (composição específica, densidade e distribuição), ao ambiente (clima, solo e manejo da cultura) e ao período em que elas convivem. Segundo Carvalho e Guzzo (2008), a composição da comunidade de plantas daninhas se destaca como um dos fatores fundamentais na determinação do grau de interferência.

As populações que compõem a comunidade infestante apresentam forte interação entre si, as quais, de acordo com Pitelli (2000), podem ser estudadas por meio de índices fitossociológicos; entre eles, o que melhor expressa essa relação é o índice de importância relativa (CARVALHO et al., 2008).

Dessa forma, objetivou-se com esta pesquisa avaliar efeitos de cultivares de alface na supressão de plantas daninhas.

\section{Material e métodos}

O experimento foi conduzido em casa de vegetação do Setor de Horticultura da Universidade Federal Rural do Rio de Janeiro - UFRRJ, em Seropédica-RJ (22 44' 38" S, 43 42' $28^{\prime \prime}$ o e $26 \mathrm{~m}$ de altitude), no período compreendido entre os meses de setembro e novembro de 2012 . Foram avaliados os componentes fitossociológicos de plantas daninhas em 12 cultivares de alface dispostas no delineamento em blocos ao acaso, com três repetições, sendo as parcelas constituídas de 12 plantas espaçadas de $0,30 \times 0,25 \mathrm{~m}$, das quais 8 foram coletadas para análise de produtividade. As cultiva- 
res avaliadas foram: do grupo lisa (Regina 2.000, Regina 500, Regina 3.500, Maravilha de Inverno, Boston Branca, Rainha de Maio); do grupo crespa (Grand Rapids, Hanson, Camila, Banchu Red Fire) e do grupo americana (Grandes Lagos, Delícia).

A semeadura da alface foi realizada no dia 11 de setembro de 2012, em bandejas de poliestireno expandido de 200 células, contendo substrato comercial para hortaliças, distribuindo-se três sementes por célula. Após a germinação, no estádio de primeira folha definitiva, foi realizado o desbaste, deixando-se apenas uma plântula por célula. As mudas foram transplantadas para o campo aos 37 dias após a semeadura, quando foram identificadas quatro folhas definitivas, no dia 18 de outubro de 2012. Utilizou-se adubação química no plantio, conforme recomendação para a cultura da alface, respeitando a análise de solo. A irrigação foi feita pelo método de gotejamento com turno de rega de 1 dia. A colheita foi realizada no dia 16 de novembro de 2012, aos 29 dias após transplantio (DAT), quando foi identificado o máximo desenvolvimento vegetativo.

Para a avaliação do comportamento da comunidade infestante durante o ciclo da cultura, realizaram-se coletas de plantas daninhas em duas épocas distintas. A primeira e segunda amostragens foram realizadas nos dias 2 e 16 de novembro, respectivamente, utilizando um quadrado de $0,25 \mathrm{~m}$ de lado, lançado aleatoriamente uma vez na parcela.

As plantas daninhas que se encontravam dentro do quadrado foram cortadas rente ao solo, sendo levadas ao laboratório para identificação, contagem do número de espécies e de indivíduos por espécie. Determinou-se a biomassa seca das plantas, após secagem em estufa a $65^{\circ} \mathrm{C}$, durante 72 horas. A partir dos dados obtidos, foram calculados os parâmetros fitossociológicos, de acordo com a fórmula proposta por Mueller-Dombois e Ellenberg (1974), em que frequência (F) representa o número de parcelas que contém a espécie/número total de parcelas utilizadas; densidade (D) = número total de indivíduos por espécie / área total amostrada; dominância (Do) = massa seca da espécie; frequência relativa $(F R)$ = frequência da espécie x 100 / frequência total das espécies; densidade relativa $(D R)=$ densidade da espécie $\times 100$ / Densidade total das espécies; Dominância Relativa (DoR) - refere-se à divisão da massa seca acumulada por uma determinada espécie pela massa seca total acumulada por toda a comunidade infestante - e índice de valor de importância (IVI) $=$ FR + $\mathrm{DR}+$ DoR.

\section{Resultados e discussão}

Foram encontradas 22 espécies de plantas daninhas, divididas em 12 famílias botânicas, na área experimental na primeira avaliação (Tabela 1). Na segunda avaliação, foram encontradas praticamente as mesmas espécies de plantas daninhas, com exceção da Ipoema quamoclit L. (Corda de viola), que não foi encontrada na amostragem anterior, totalizando assim 21 espécies (Tabela 1). Apesar de não haver mudanças nas espécies de plantas daninhas entre épocas de avaliação na área total experimental, houve redução tanto no número de indivíduos por espécies quanto na massa seca. Entretanto, não houve alteração na ordem determinada pelo valor de importância das três primeiras: C. esculentus L.(Tiririca), C. benghalensis L. (Trapoeraba) e P. maximum Jacq (Capim Colonião), na área total experimental, sendo essas as que apresentam os valores mais expressivos. 
Tabela 1. Espécies de plantas identificadas na primeira e segunda avaliação.

\begin{tabular}{|c|c|c|}
\hline NOME COMUM & NOME CIENTÍFICO & FAMÍLIA BOTÂNICA \\
\hline Beiço de Boi & Desmodium tortuosum (Sw.) DC. & Fabaceae \\
\hline Beldroega & Portulaca oleracea L. & Portulacaceae \\
\hline Capim Colonião & Panicum maximum Jacq. & Poaceae \\
\hline Caruru & Amaranthus retroflexus L. & Amaranthaceae \\
\hline Erva Andorinha & $\begin{array}{l}\text { Chamaesyce hyssopifolia (L.) } \\
\text { Small. }\end{array}$ & Euphorbiaceae \\
\hline Erva de Santa Luzia & Chamaesyce hirta (L.) Millsp. & Euphorbiaceae \\
\hline Falsa Serralha & Emilia sonchifolia DC. & Asteraceae (Compositae) \\
\hline Flor de Cardeal & Ipomoea quamoclit L. & Convolvulaceae \\
\hline Guanxuma & Sida glaziovii K. Schum. & Malvaceae \\
\hline Joá de Capote & Nicandra physaloides Gaertn. & Solanaceae \\
\hline Leiteira & Euphorbia heterophylla L. & Euphorbiaceae \\
\hline Maria Pretinha & Solanum americanum Mill. & Solanaceae \\
\hline Mata Pasto & Diodia teres Walt. & Rubiaceae \\
\hline Mussambê & Cleome affinis DC. & Brassicaceae \\
\hline Pé de Galinha & Eleusine indica (L.) Gaertn. & Poaceae \\
\hline Picão & Bidens pilosa L. & Asteraceae (Compositae) \\
\hline Picão Branco & Galinsoga parviflora Cav. & Asteraceae (Compositae) \\
\hline Poaia Branca & Richardia brasiliensis Gomez. & Rubiaceae \\
\hline Quebra Pedra & Phyllanthus tenellus Roxb. & Euphorbiaceae \\
\hline Quebra Pedra II & Phyllanthus sp. L. & Euphorbiaceae \\
\hline Tiririca & Cyperus esculentus L. & Cyperaceae \\
\hline Trapoeraba & Commelina benghalensis L. & Commelinaceae \\
\hline
\end{tabular}

Na Figura 1, apresentada a seguir, estão expostos os valores de importância das plantas daninhas na primeira e segunda avaliação, considerando a área total do experimento. Nota-se que as três principais plantas daninhas encontradas, em ambas as avaliações, foram C. esculentus L., C. benghalensis L. e P. maximum Jacq. indicando que essas espécies foram as que possuíram maior potencial de competição com a cultura da alface nas condições avaliadas. Esse potencial competitivo elevado pode ser explicado pela adaptabilidade dessas espécies ao sistema de cultivo empregado, em que há disponibilidade ótima de recursos como água, luz e nutrientes no solo, proporcionando a elas rápido desenvolvimento, capaz de competir com a cultura da alface e com as demais espécies de plantas daninhas presentes na área. Soma-se a isso o fato de as duas primeiras espécies (C. esculentus L. e $C$. benghalensis L.) serem de propagação vegetativa, o que proporciona o desenvolvimento inicial mais vigoroso das plantas. Segundo Melhorança Filho et al. (2008), a presença de plantas de $C$. rotundus L. interferiu na germinação, crescimento e desenvolvimento das plantas de alface $\mathrm{cV}$ Lucy Brown. Períodos prolongados de competição induzem a redução da área foliar da alface e, consequentemente, interferem em sua produtividade. 

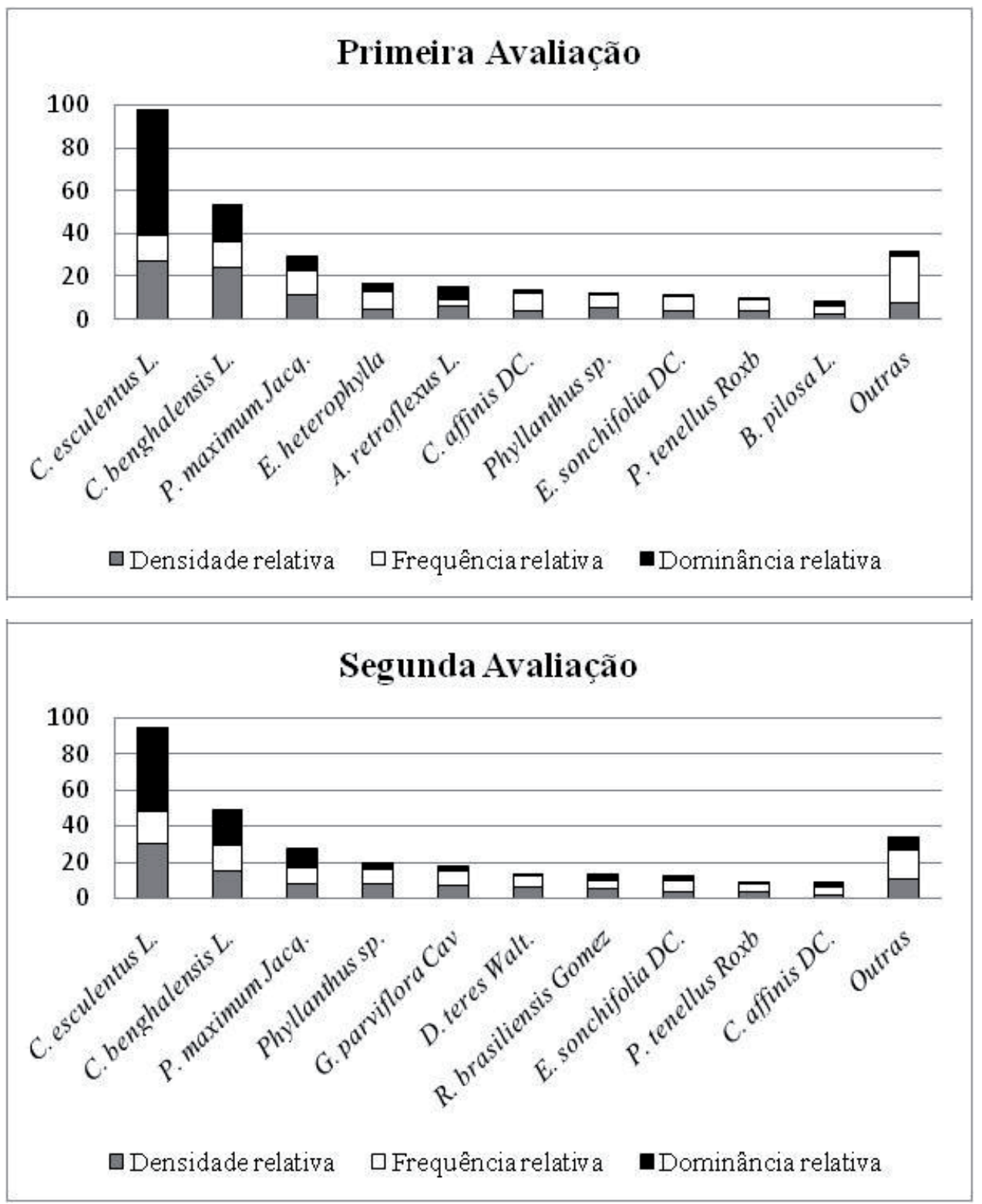

Figura 1. Densidade total, frequência relativa total e dominância relativa total de plantas daninhas na cultura da alface em função da época de avaliação.

Fonte: Elaboração dos autores.

A redução no valor de importância na maioria das espécies na segunda avaliação pode estar relacionada à maior cobertura do solo pelo desenvolvimento da alface, impedindo o pleno desenvolvimento das plantas daninhas. Além disso, a maior parte do banco de sementes presente na área provavelmente se encontra dormente, visto que o tempo, após a eliminação dessas plantas daninhas pela capina manual logo a seguir da primeira avaliação, não foi suficiente para a quebra dessa dormência, limitando, assim, a reinfestação da área. Ocorreram elevações na densidade relativa das espécies, relacionadas ao aumento do número de plantas por área, e uma redução no valor de dominância relativa, relacionada à massa seca das plantas, reforçando a ideia do sombreamento causado pelo desenvolvimento da alface (Figura 1 ).

No que diz respeito à relação entre cultivares de alface e comportamento da comunidade infestante na área experimental, o parâmetro que mais contribuiu para a determinação do valor de importância das plantas daninhas, em todos os tratamentos, foi a dominância relativa (Figuras 2, 3 e 
4). Esse fator está ligado diretamente à massa seca das plantas, ou seja, quanto maior a massa seca maior a dominância da espécie, indicando que as principais espécies de plantas daninhas identificadas apresentaram melhor desenvolvimento e acúmulo de massa, o que está diretamente relacionado com a capacidade competitiva e com o potencial de gerar prejuízos à produtividade das cultivares de alface.

Verifica-se, nas figuras 2, 3 e 4, que há forte redução no valor de dominância relativa das plantas daninhas, em todas as cultivares de alface avaliadas, bem como no número de espécies encontradas, quando se comparam as duas avaliações. Essa redução está diretamente relacionada com a diminuição da massa seca das plantas daninhas na segunda avaliação, provocada pelo desenvolvimento das cultivares de alface, ao proporcionarem maior cobertura do solo e menor desenvolvimento das plantas daninhas. As cultivares de alface de melhor desenvolvimento vegetativo, consequentemente, de maior cobertura do solo, prejudicaram as plantas monocotiledôneas, mais dependentes de luz. Houve mudança na ordem das plantas daninhas quanto ao valor de importância, já que espécies monocotiledôneas de metabolismo $\mathrm{C}_{4}$, com maior valor de importância na primeira avaliação, cederam lugar às espécies eudicotiledôneas de metabolismo $\mathrm{C}_{3}$, coincidindo justamente com as cultivares de maior desenvolvimento, a Regina 2.000, Regina 3.500 e Rainha de Maio. 


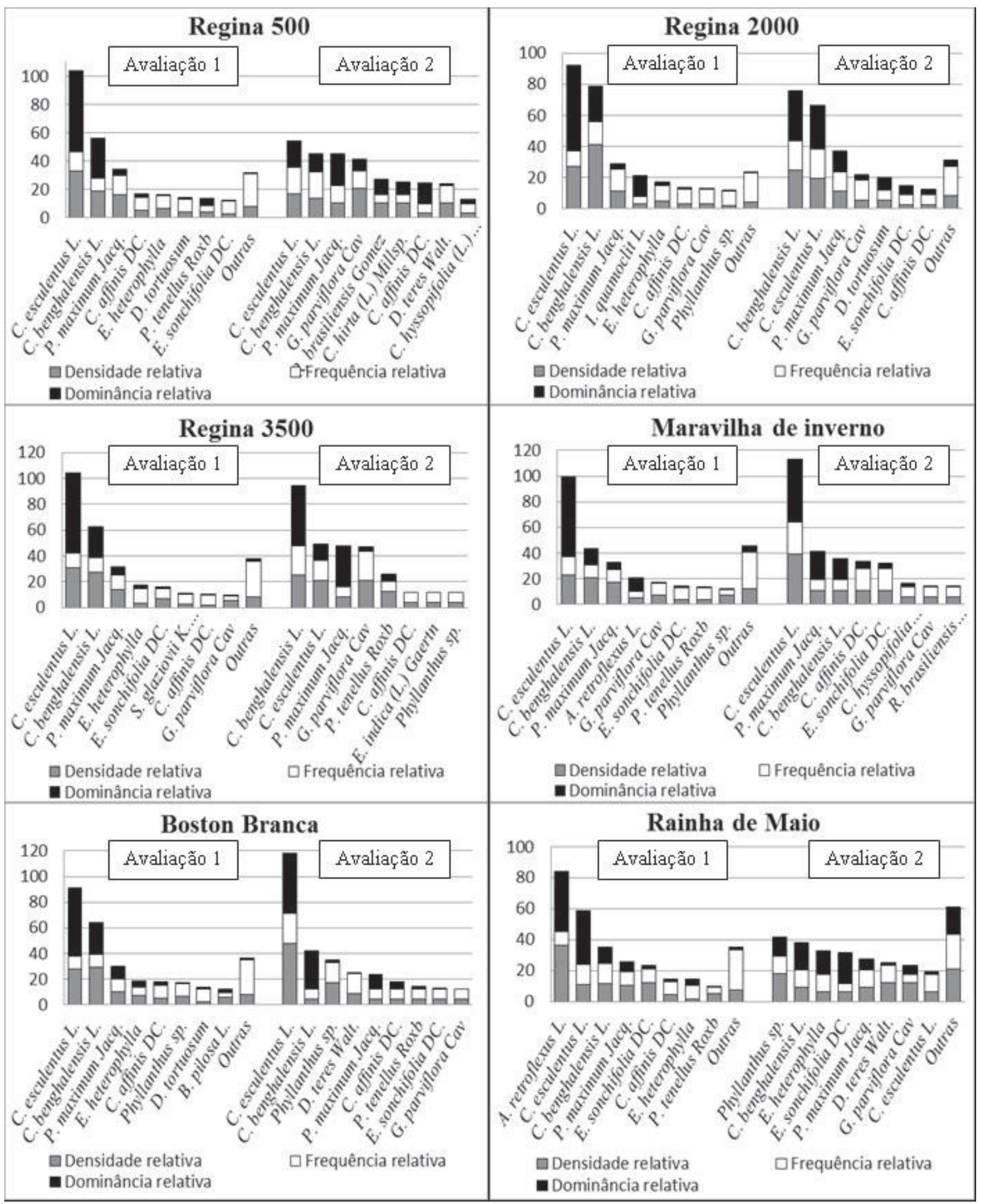

Figura 2. Densidade relativa (DR), frequência relativa (FR), dominância relativa (DoR) de plantas daninhas em cultivares de alface do grupo lisa.

Fonte: Elaboração dos autores. 


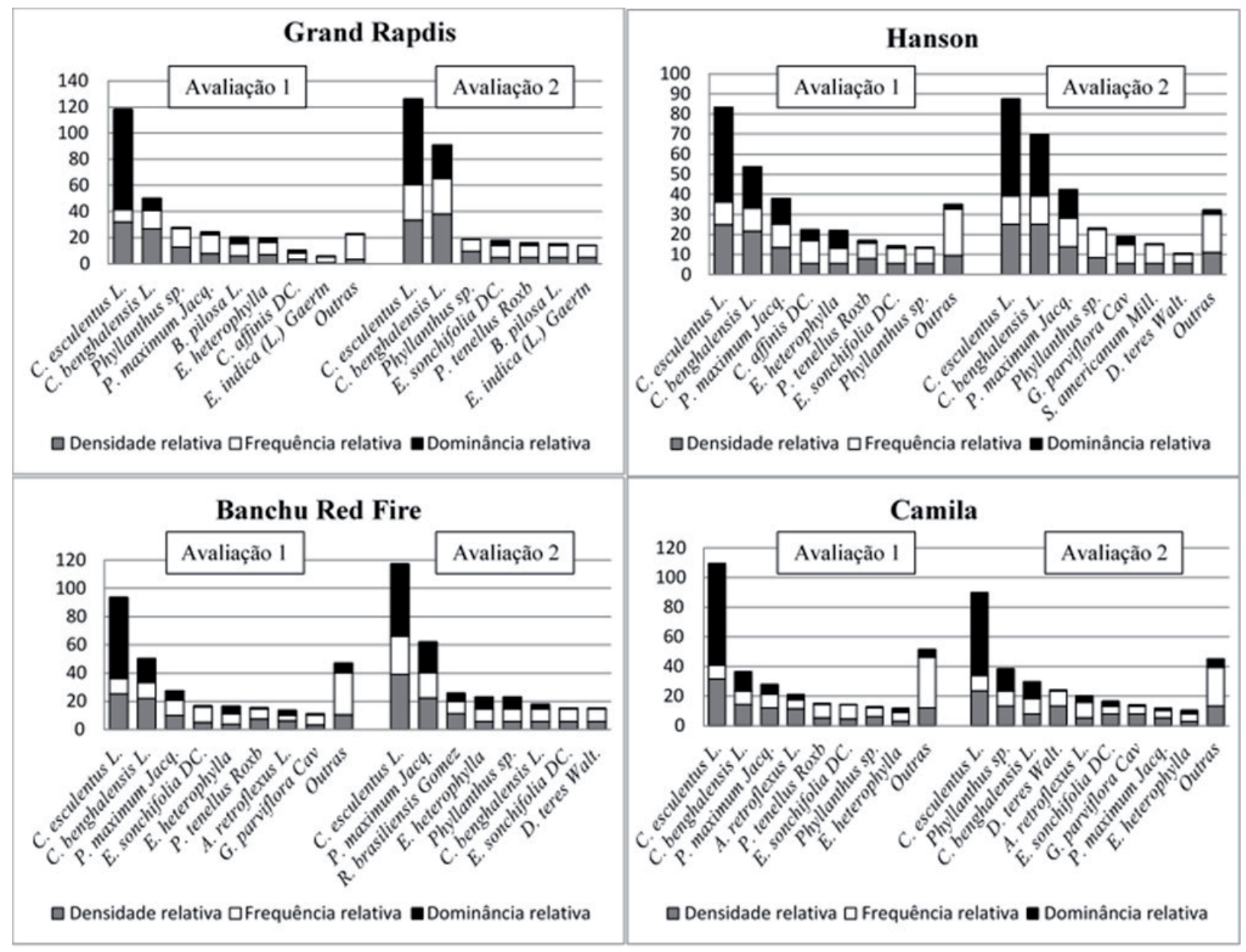

Figura 3. Densidade relativa (DR), frequência relativa (FR), dominância relativa (DoR) de plantas daninhas em cultivares de alface do grupo crespa.

Fonte: Elaboração dos autores. 


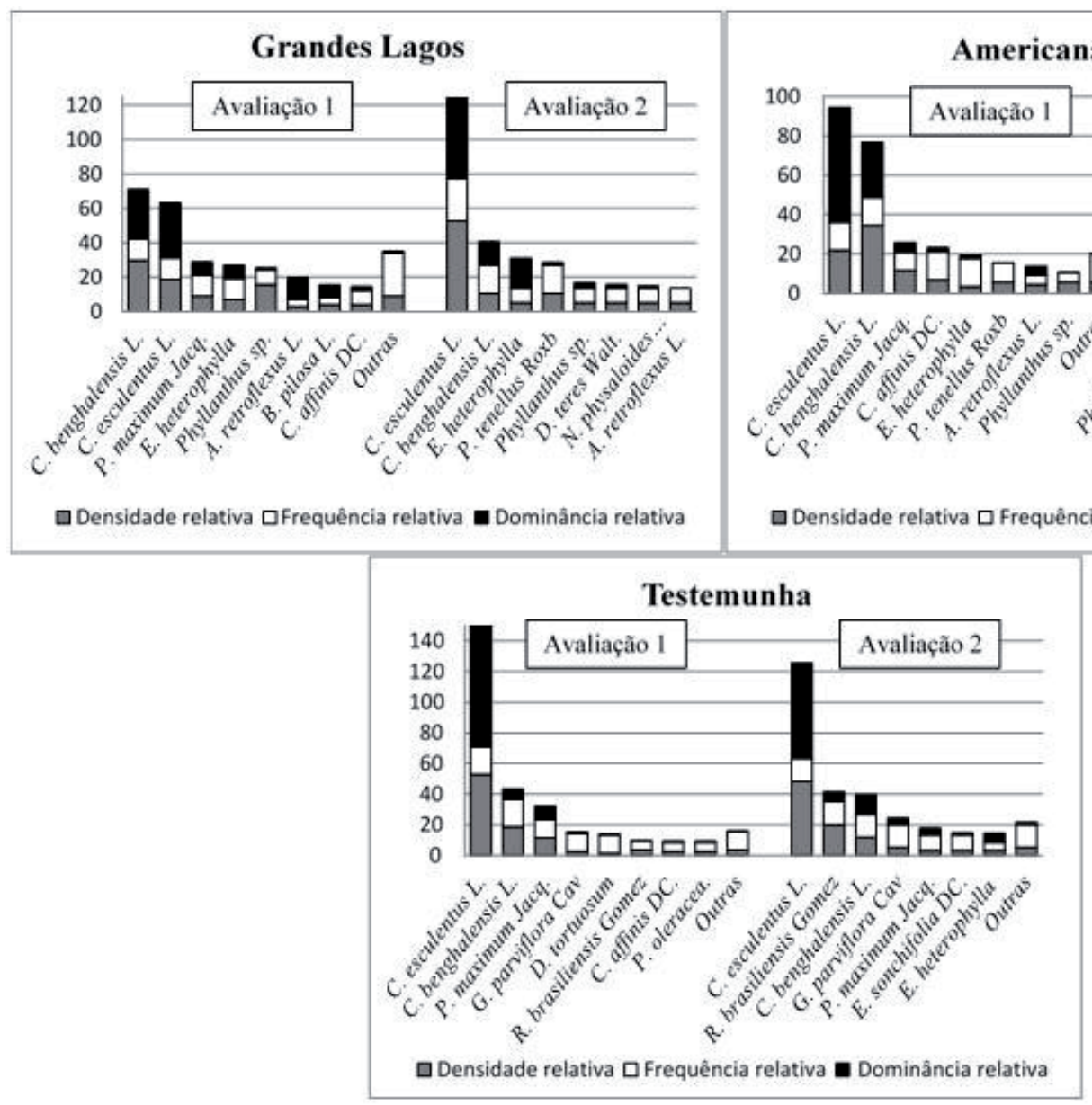

Figura 4. Densidade relativa (DR), frequência relativa (FR), dominância relativa (DoR) de plantas daninhas em cultivares de alface do grupo americana.

Fonte: Elaboração dos autores.

Resultados obtidos por Melhorança Filho et al. (2008) indicaram que o desenvolvimento da alface cv. Lucy Brown, na presença de plantas daninhas, a partir do sétimo dia após o transplantio, provocou aumento nos valores de área foliar da cultivar. Atribui-se tal resultado ao fato de que a cultura minimiza os efeitos da competição com o sombreamento dessas plantas. Giancotti et al. (2010) discutiram trabalhos em que se avaliaram diferentes épocas de período total de prevenção à interferência, que variam de 14 a 21 dias, e atribuíram as diferenças ao crescimento mais rápido ou mais lento das cultivares avaliadas. Cultivares que ocasionam o fechamento do solo e sombreamento da entrelinha minimizam a interferência das plantas daninhas na produção.

A densidade relativa, a frequência relativa e a dominância relativa na segunda avaliação para a C. esculentus L. aumentaram no tratamento da cultivar Grandes Lagos (Figura 4). A alface do tipo americana, pelo longo período para formação de cabeça, apresentou menor desenvolvimento e cobertura do solo, podendo ter favorecido o desenvolvimento da referida espécie de planta daninha. De acordo com Sediyama et al. (2009), as cultivares do grupo americana são, normalmente, mais tardias e chegam a apresentar um ciclo vegetativo entre 70 e 90 dias.

Observou-se melhor desempenho vegetativo para as cultivares de folha lisa no presente experimento. Não foram obtidos dados quantitativos para essa característica, impossibilitando a aplicação de um método estatístico paramétrico. Porém, foi nítida a diferença na cobertura do solo entre as cultivares. 
O padrão de dispersão e germinação das plantas daninhas pode influenciar no seu potencial competitivo, causando maior ou menor prejuízo às culturas de interesse. Essas características explicam o fato do Amaranthus retroflexus L. (caruru) possuir o maior valor de importância apenas na cultivar Rainha de Maio, na primeira avaliação, já que seu valor de importância nas demais cultivares não se destaca perante as outras espécies de plantas daninhas. O A. retroflexus L. (caruru) apresenta germinação abundante e concentrada nessa cultivar, provavelmente em razão da presença anterior de uma ou mais plantas que produziram e dispersaram sementes em uma área restrita.

Com relação à $C$. benghalensis L., observa-se o aumento do valor de importância da primeira para a segunda avaliação no grupo lisa, exceto para as cultivares Regina 2.000 e Maravilha de Inverno. Contudo, em todas as cultivares desse grupo, foi observado incremento no índice dominância relativa da referida espécie. Por ser uma espécie de propagação vegetativa, a C. benghalensis L. possui a habilidade de desenvolver rapidamente os propágulos presentes na área e de competir com a cultura de interesse, investindo em biomassa seca de parte aérea por meio da máxima extração de recursos do meio.

\section{Conclusão}

Conclui-se, a partir deste trabalho, que as três principais plantas daninhas, com relação ao valor de importância, identificadas na área experimental do setor de horticultura da UFRRJ, foram a C. esculentus L.(Tiririca), C. benghalensis L. (Trapoeraba) e P. maximum Jacq. (Capim Colonião), em ambas as avaliações.

As cultivares do grupo lisa Regina 500, Regina 2.000, Regina 3.500 e Rainha de Maio provocaram maiores reduções dos valores de dominância relativa na segunda avaliação.

\section{Weed population dynamics in lettuce cultivars produced in summer in Seropédica-RJ}

\section{Abstract}

The production of vegetables is usually carried out through intensive farming system, being affected by weed competition. This paper aims to assess the effects of 12 lettuce varieties in order to reduce weeds. The experimental design was randomized blocks, three replications and 12 plant plots distributed into four $0.30 \mathrm{~m}$ spaced lines. The cultivars were loose leaf group (Regina 2.000, Regina 500, Regina 3.500, Maravilha de Inverno, Boston Branca, Rainha de Maio); crisp leaf group (Grand Rapids, Hanson, Camila, Banchu Red Fire) and american group (Grandes Lagos and Delícia). The weeds were evaluated 15 and 29 days after transplanting, being identified and determined the number of species and individuals for species. From these data, the Frequency (F), Density (D), Dominance (DO), Relative Frequency (FR), Relative Density (DR), Relative Dominance (DOR) and Importance Value Index (IVI) were determined. The three main weed identified, concerning its importance value, were Cyperus esculentus L., Commelina benghalensis L. e Panicum maximum Jacq. The loose leaf variety group Regina 500, Regina 2.000, Regina 3.500 and Rainha de Maio resulted in larger reductions in all weeds species on the second evaluation.

Keywords: Lactuca sativa L. Vegetables. Weeds. 


\section{Referências}

CARVALHO, L. B.; GUZZO, C. D. Adensamento da beterraba no manejo de plantas daninhas. Planta Daninha, Viçosa, v. 26, n. 1, p. 73-82, jun. 2008.

CARVAlHO, L. B.; PITELLI, R. A.; CECÍLIO FILHO, A. B.; BIANCO, S.; GUZZO, C. D. Interferência e estudo fitossociológico da comunidade infestante em beterraba de semeadura direta. Planta Daninha, Viçosa, v. 26, n. 2, p. 291-299, jun. 2008.

ECHER, M. M.; SIGRIST, J. M. M.; GUIMARÃES, V. F.; MINAMI, K. Comportamento de cultivares de alface em função do espaçamento. Revista de Agricultura, Piracicaba, v. 76, n. 2, p. 267-275. 2001.

FONTANÉTTI, A.; CARVAlHO, G. J.; AUgUStO, R. M. A. R.; ALMEIDA, K.; DUARTE, W. F. Adubação verde no controle de plantas invasoras nas culturas de alface-americana e de repolho ciência. Agrotécnica, Lavras, v. 28, n. 5, p. 967-973, set./out. 2004.

GIANCOTTI, P. R. F.; MACHADO, M. H.; YAMAUTI, M. S. Período total de prevenção à interferência das plantas daninhas na cultura da alface cultivar Solaris. Semina: Ciências Agrárias, Londrina, v. 31 , suplemento 1, p. 1299-1304. 2010.

GIANNOPOLITIS, C.N.; VASSILIOU, G.; VIZANTINOPOULOS, S. Effects of weed interference and herbicides on nitrate and carotene accumulation in lettuce. Journal Agricultural Food Chemistry. Washington, v. 37, n. 2, p. 312-315, Mar. 1989.

LORENZI, H. Manual de identificação e controle de plantas daninhas: plantio direto e convencional. 7. ed. São Paulo: Instituto Plantarum, 2006. 384 p.

MELhORANÇA FILHO, A. L.; PEREIRA, M. R. R.; MARTINS, D.; CASTRO, R. M.; NASCIMENTO, M. S. Produtividade de alface cv. Lucy Brown influenciada por períodos de convivência com plantas infestantes e potencial alelopático da tiririca. Bioscience Journal, Uberlândia, v. 24, n. 3, p. 19-23, July/Sept. 2008.

MUELLER-DOMBOIS, D.; ELLENBERG, H. Aims and methods of vegetation ecology. New York: John Wiley \& Sons, 1974. 547 p.

PITELLI, R. A. Estudos fitossociológicos em comunidades infestantes de agroecossistemas. Jornal Conserb, Washington, v. 1, n. 2, p. 1-7. 2000.

PITELLI, R.A. Interferência de plantas daninhas em culturas agrícolas. Informe Agropecuário, Belo Horizonte, v. 11, n. 129, p. 19-27, 1985.

SEDIYAMA, M. A. N.; PEDROSA, M. W.; SALGADO, L. T.; PEREIRA, P.C.; Desempenho de cultivares de alface para cultivo hidropônico no verão e no inverno. Científica, Viçosa, v. 37, n. 2, p. 98-106. 2009.

ZANATTA, F. J.; FIGUEIREDO, S.; FONTANA, L. C.; PROCÓPIO, S. O. Interferência de plantas daninhas em culturas olerícolas. Revista da FZVA, Uruguaiana, v. 13, n. 2, p. 39-57. 2006.

\section{Histórico editorial}

Submetido em: 16/10/2014

Aceito em: 04/03/2015 